\title{
Inferring functional extinction based on sighting records
}

\author{
Ivan Jarić ${ }^{1,2^{*}}$, Jörn Gessner ${ }^{1}$ and Andrew R. Solow ${ }^{3}$ \\ ${ }^{1}$ Leibniz-Institute of Freshwater Ecology and Inland Fisheries, Müggelseedamm 310, 12587 \\ Berlin, Germany \\ ${ }^{2}$ Institute for Multidisciplinary Research, University of Belgrade, Kneza Viseslava 1, 11000 \\ Belgrade, Serbia \\ ${ }^{3}$ Woods Hole Oceanographic Institution, Woods Hole, MA 02543, USA \\ * Author to whom correspondence should be addressed: Leibniz-Institute of Freshwater Ecology \\ and Inland Fisheries, Müggelseedamm 310, 12587 Berlin, Germany; E-mail: jaric@igb- \\ berlin.de; phone: +49(0)3064181 766, fax.: +49(0)3064181626
}




\begin{abstract}
The term functional extinction is used to describe a permanent failure of reproduction or recruitment in a population. Functional extinction results in a truncation of the age distribution, but this can be very difficult to detect in poorly studied populations. Here, we describe a novel statistical method for detecting functional extinction based on a sighting record of individuals of known or estimated ages. The method is based on a simple population dynamics model and simulation results show that it works well even with limited data. The method is illustrated using a sighting record of the ship sturgeon (Acipenser nudiventris) in the Danube River. The results indicate that this population is functionally extinct, most likely by 2002. Management implications of this finding are discussed.
\end{abstract}

Keywords: Acipenser nudiventris, extinction risk, recruitment failure, reproductive failure, sighting record 


\section{INTRODUCTION}

For many species, negative population trends pass largely undetected across the critical point beyond which management and conservation measures become ineffective, while the likelihood of extinction approaches certainty. As a result, timely and reliable detection of critical population status is of paramount importance to allow effective countermeasures to be taken in due time.

One of the frequently observed patterns that precede extinction of a species is the process of time-delayed deterministic extinction (Ford et al., 2009), which commonly occurs due to persistent lack of reproduction success or recruitment. Such populations are typically represented by a slowly declining number of adults that are no longer able to successfully reproduce (Evans and Keen, 2013). This phenomenon was recognized as the major extinction threat in populations of many species, such as wolf (Canis lupus; Bull et al., 2009), baiji (Lipotes vexillifer; Xu et al., 2012), tuatara (Sphenodon punctatus; Grayson et al., 2014), giant clam (Tridacna maxima; Waters et al., 2013) and different bird species (Donald, 2007), and it was denoted as 'reproductive extinction' (Peterson et al., 2001), 'latent extinction' (Evans and Keen, 2013), 'virtual extinction' (Peterson et al., 2001), and 'living dead'-phenomenon (Janzen, 2001 cit. in Evans and Keen, 2013). However, following Ricciardi et al. (1998), Bull et al. (2009), Waters et al. (2013), and others, we refer to a permanent lack of reproductive or recruitment success as functional extinction. It is important to note that the term functional extinction, as it was used in the present study, should not be confused with other uses of this term in literature (Jarić, 2015).

Functional extinction can be particularly difficult to detect, especially in long-lived species, where the point of no return is often crossed long before the actual extinction occurs. In such populations, older individuals tend to remain present for years after the last successful 
reproduction event, thus presenting a false image of population viability. Furthermore, for rare or poorly studied species, sighting records often represent the only available source of data for the quantitative assessment of population status (Solow, 1993, 2005). In such circumstances, development of quantitative methods to allow inferences about functional extinction based on limited data available would be valuable.

In this paper, we describe a novel statistical method for inference about functional extinction based on sighting records. The method is illustrated using a sighting record of the ship sturgeon (Acipenser nudiventris) in the Danube River.

\section{MODEL AND METHOD}

In this section, we describe a statistical model of a sighting record of individuals of known ages and the use of this model for inference about functional extinction and its timing.

We begin by describing a model of the unobserved variations in abundance of the species in question. Consider the observation period $t=1,2, \ldots, T$ and let the unobserved abundance in year $t$ of a cohort spawned in year $j$ be:

$Y_{j t}=Y_{j} \exp (-\beta(t-j)) \quad t=j, j+1, \ldots, T$

where $Y_{j}$ is the initial cohort size and $\beta$ is the annual mortality rate. Let $\tau_{E}$ be the last year before functional extinction, so that $Y_{j}=0$ for $j>\tau_{E}$. Populations typically experience large inter-annual fluctuations in year-class strength, often connected to environmental variations. To capture this, we will assume that, for $j \leq \tau_{E}, Y_{j}$ is an exponential random variable with probability density function: 
$f\left(y_{j}\right)=\theta \exp \left(-\theta y_{j}\right)$

where the unknown parameter $\theta$ is the reciprocal of mean initial cohort size. Let $Y=\left(Y_{1}, Y_{2}, \ldots\right.$, $\left.Y_{T}\right)$.

We consider next a model of sampling from this population. A random sample of $m_{t}$ individuals is collected in year $t\left(m_{t}\right.$ may be 0$)$ and the age of each individual is recorded. Individuals from cohorts outside the observation period are not included in this sample. Let $X_{j t}$ be the number of these individuals that come from cohort $j$ and let $X_{t}=\left(X_{1}, X_{2 t}, \ldots, X_{t t}\right)$ be the vector of these numbers. Conditional on the observed value $m_{t}$, and on the unobserved vector of initial cohort sizes $y=\left(y_{1}, y_{2}, \ldots, y_{t}\right), X_{t}$ has a multinomial distribution with probability mass function:

$\operatorname{pr}\left(x_{t} \mid m_{t}, y\right)=\frac{m_{t} !}{\prod_{j=1}^{t} x_{j t} !} \prod_{j=1}^{t} p_{j t}{ }_{j t}^{x_{j t}}(y)$

where:

$$
p_{j t}(y)=\frac{y_{j} \exp (-\beta(t-j))}{\sum_{k=1}^{t} y_{k} \exp (-\beta(t-k))}
$$

The conditioning on the unobserved $y$ can be removed by integrating $\operatorname{pr}\left(x_{t} \mid m_{t}, y\right)$ over the distribution of $Y$ leading to the probability mass function $\operatorname{pr}\left(x_{t} \mid m_{t}\right)$ of $X_{t}$ conditional on the observed $m_{t}$ alone. Importantly, because the conditional distribution of $X_{t}$ given $m_{t}$ depends only 
on the relative cohort abundances in year $t, \operatorname{pr}\left(x_{t} \mid m_{t}\right)$ does not depend on the unknown parameter $\theta$. In practice, this probability mass function can be approximated by:

$$
p r\left(x_{t} \mid m_{t}\right) \cong \frac{m_{t} !}{\prod_{j=1}^{t} x_{j t} !} \sum_{b=1}^{B} \prod_{j=1}^{t} \frac{p_{j t}^{x_{j t}}(y(b))}{B}
$$

where B is a large number and $y(b)=\left(y_{1}(b), y_{2}(b), \ldots, y_{T}(b)\right)$ and where $y_{j}(b)$ is a value simulated from an exponential distribution with mean 1. For later use, the log likelihood function for this model is given by:

$\log L\left(\tau_{E}, \beta\right)=\sum_{t=1}^{T} \log p r\left(x_{t} \mid m_{t}\right)$

where $x_{t}$ is the vector of observed cohort counts in the sample in year $t$.

We turn now to statistical inference about $\tau_{E}$ based on the model described above. Interest here centers on testing the null hypothesis $H_{0}: \tau_{E}=T$ that functional extinction has not occurred during the observation period against the alternative hypothesis $H_{1}: \tau_{E}<T$ that it has and, in the event that $H_{0}$ is rejected, in constructing a confidence interval for $\tau_{E}$. A natural statistic for testing $H_{0}$ against $H_{1}$ is the year $R$ of the most recent observed cohort, with $H_{0}$ being rejected for small values of $R$.

The significance of the observed value of $R$ can be approximated via the following parametric bootstrap. As above, initial cohort sizes $y_{1}, y_{2}, \ldots, y_{T}$ are simulated from the unit exponential distribution. Using these initial cohort sizes, for $k=1,2, \ldots, T, x_{k}$ is simulated from the multinomial distribution with $m_{k}$ trials and probabilities given in (4) with $\beta$ equal to its 
maximum likelihood (ML) estimate $\hat{\beta}\left(\tau_{E}\right)$ with $\tau_{E}$ fixed at $T$. The value of $R$ for the simulated dataset is recorded, and the procedure is repeated a large number of times. The significance level (or $p$ value) can be approximated by the proportion of simulated values of $R$ that exceed the observed value plus half of the proportion that are equal to the observed value. This is an application of the so-called mid- $p$ method (Berry and Armitage, 1995).

The upper bound of a one-sided 1 - $\alpha$ confidence interval for $\tau_{E}$ is given by the largest value of $\tau_{0}$ for which the null hypothesis $H_{0}: \tau_{E}=\tau_{0}$ cannot be rejected at significance level $\alpha$ against the alternative hypothesis $H_{1}: \tau_{E}<\tau_{0}$. The parametric bootstrap outlined above can be used to test $H_{0}$ against $H_{1}$. In this case, initial cohort size $y_{k}$ is 0 for $k>\tau_{0}$ and the value of $\beta$ used to form the multinomial probabilities is the ML estimate $\hat{\beta}\left(\tau_{0}\right)$ with $\tau_{E}$ fixed at $\tau_{0}$.

\section{SIMULATION RESULTS}

We conducted a simulation study to assess the performance of the test for functional extinction described in the previous section. This involved repeatedly simulating data from the underlying model for selected values of the parameters $\beta$ and $\tau_{E}$, applying the test to the simulated data at significance level 0.05 , and recording the rate at which the null hypothesis $H_{0}$ that functional extinction has not occurred was rejected. In each case, the length of the observation period was fixed at 50 years and individuals were sampled at ten-year intervals. We considered 3 possible values of the number of individuals sampled at each of these times: 1, 3, and 5.

The goal of the first part of the study was to assess the agreement between the nominal 0.05 significance level and the rate at which $H_{0}$ is rejected when it is true. The results are presented in Table 1, with each entry based on 2000 simulated datasets and 1000 parametric 
bootstrap samples for each of these. The agreement between the nominal and actual significance levels is generally good with a slight tendency for the test to be conservative when the annual mortality rate $\beta$ is low.

The goal of the second part of the study was to assess the power of the test- that is, the rate at which $H_{0}$ is rejected when it is false. The results of this part of the study are presented in Table 2, with each entry based on 1000 simulated datasets and 1000 bootstrap samples for each. The test has good power in all cases except when $\beta$ is low and the number of sampled individuals is small.

\section{APPLICATION}

We illustrate the method application by using a dataset on sightings of ship sturgeon from the Danube River. This species inhabits Black, Caspian and Aral Sea basins, and it is considered as critically endangered throughout its range (Gessner et al., 2010). It was once commonly recorded in the Danube (Hensel and Holčik, 1997) but since the mid-1950s the population has been severely depleted by a combination of factors and there is concern that it has failed to reproduce over a prolonged period (Jarić et al., 2009; Gessner et al., 2010). Due to a lack of systematic monitoring, the ship sturgeon population in the Danube River is known only through a small number of chance sightings and drawing conclusions about its population status is challenging.

The beginning of the observation period was set at 1955. Only 13 sightings of ship sturgeon have been confirmed between 1955 and 2015 (Table 3). Of these, it is possible to estimate the ages of 12 specimens based on a regression of body length and weight (Holčik, 1989), while using the correction factor for age assignment by Bruch et al. (2009; see online 
Appendix). Four specimens were omitted from the analysis, since they belonged to cohorts spawned before the beginning of the observation period. Although the number of aged specimens is greater in recent years, the overall sighting rate has remained stable since 1955.

We applied the test for functional extinction to the data in Table 3. The approximate $p$ value based on 10000 parametric bootstrap samples was around 0.03 and, by conventional standards of significance, we reject the null hypothesis that functional extinction has not yet occurred. The upper bound of an approximate one-sided 0.95 confidence interval for $\tau_{E}$ is 2002 . The maximum likelihood estimates of the annual mortality rate $\beta$ ranged from 0.062 to 0.093 for values of $\tau_{E}$ in this confidence interval. These are generally consistent with values in the literature (Jarić et al., 2010).

Finally, to assess the robustness of the result of the test to errors in the estimated ages, we applied the test to 1000 datasets generated by randomly perturbing each of the age estimates in Table 3 by up to 3 years. Of the $1000 p$ values generated in this way, 772 were less than 0.05 and none was larger than 0.09 .

\section{DISCUSSION}

This paper presents a novel statistical approach to infer functional extinction. The statistical method described here is based on a very simple model of population dynamics. This level of simplicity is necessitated by the fact that the population and its demography are known only through a very small number of captured individuals. Its data requirements are also low, which facilitates its application for data-deficient situations. Necessary input data are simple sighting records, with the time of sighting and the age estimation of each recorded specimen. With more data, it would be possible to evaluate and, if necessary, elaborate this model. 
The method application was illustrated on a sighting record of the Danube River ship sturgeon. The results indicated that this population is indeed functionally extinct, with functional extinction most likely occurring by 2002 . With remaining individuals being at least 13 -years old, extinction is expected to occur within the next 20 years, based on the expected lifespan of the species. It is likely that functional extinction might be widespread within this group of fish, and that it has already occurred in other sturgeon and paddlefish populations. Lack of successful reproduction or recruitment was reported in a number of sturgeon and paddlefish populations, for example in European sturgeon (A. sturio) in the Gironde Estuary in France, where the last confirmed natural reproduction occurred in 1994 (Williot et al., 2009), as well as in Chinese paddlefish (Psephurus gladius) in the Yangtze River in China (Zhang et al., 2009), pallid sturgeon (Scaphirhynchus albus) in the Mississippi and Missouri Rivers in USA (Webb et al., 2005), and other cases. To what degree the mentioned populations face the risk of functional extinction remains yet to be tested. In some populations, broodstock establishment and supportive stocking were introduced at one point in time to compensate for the lack of reproduction and/or recruitment (Webb et al., 2005; Williot et al., 2009; Zhang et al., 2011). In the case of the Danube ship sturgeon, species rarity and lack of adequate efforts so far prevented establishment of broodstock, despite the fact that this remains recognized as one of the current management priorities (Bloesch et al., 2006).

The common cause of functional extinction is the persistent reproductive failure, which can occur due to different factors and mechanisms such as the lack of habitat, sterility or embryo mortality induced by genetic erosion, mutations, inbreeding or pollution, catastrophic events, phenological shifts caused by climate change, parasitism, diseases, invasive species, sex-ratio bias, and population fragmentation (Loehle and Li, 1996; Janssen and Jude, 2001; Smithers et 
al., 2003; Brodie et al., 2006; Taylor et al., 2006; Engelstädter and Hurst, 2009; Finger et al., 2011; Kudo and Ida, 2013; Grayson et al., 2014). Alternatively, persistent lack of recruitment, due to continuous elevated mortality of early life phases, represents another cause of functional extinction (Webb et al., 2005). The above mentioned mechanisms are more likely to occur in small or declining populations, where various factors can contribute to reproductive failure synergistically, such as inbreeding, Allee effect, reproductive asynchrony or demographic stochasticity (McCarthy, 1997; Peterson et al., 2001; Calabrese and Fagan, 2004; Waters et al., 2013). Besides fish, reproductive failure has been reported in many other species groups, including mammals (Brodie et al., 2006; Bull et al., 2009), birds (Smithers et al., 2003; Bolger et al., 2005), reptiles (Grayson et al., 2014), amphibians (Taylor et al., 2006), molluscs (Peterson et al., 2001; Waters et al., 2013) and plants (Loehle and Li, 1996; Warburton et al., 2000; Finger et al., 2011; Evans and Keen, 2013).

One of the key problems regarding functional extinction is that it can represent a slow and long-lasting process. This may make it difficult to identify before the population approaches actual extinction, since the process of adult mortality may extend over more than a century (Evans and Keen, 2013). The American chestnut (Castanea dentata) population has managed to persist as stump sprouts for decades, in spite of a loss of reproductive ability (Loehle and Li, 1996). In addition, some forms of functional extinction may be less detectable. For instance, in sexually monomorphic species, functional extinction resulting from a population comprised of specimens of only one sex may be difficult to distinguish (Donald, 2007).

Based upon the results of the test developed, the likelihood of functional extinction can be assessed based on the sightings of individuals and their age. The method is able to indicate whether natural recovery of the population under natural conditions will be impossible, and 
provide early warning signs that countermeasures need to be taken to prevent such situation. The method also makes it possible to assess the risk of functional extinction, which may allow managers to come to a timely decision whether it is necessary to invest into ex situ measures, or the in situ conservation measures would suffice to prevent the species in question from extinction. As a result, the test has potential as a decision support tool in conservation management, and might be of value for the scientific community, wildlife managers, decision makers and other stakeholders involved in the conservation management of rare or endangered species.

\section{ACKNOWLEDGEMENTS}

The authors thank Dr Harka Ákos, Dr Zoltán Sallai and Dr Gábor Guti for providing information on ship sturgeon observations, Dr David L. Roberts for valuable comments and suggestions on an earlier version of this manuscript, as well as three anonymous reviewers for for providing helpful comments and suggestions. The authors also acknowledge the sponsorship provided by the Alexander von Humboldt Foundation and the Federal German Ministry for Education and Research, as well as the support by the Project No. 173045, funded by the Ministry of Education, Science and Technological Development of the Republic of Serbia.

\section{REFERENCES}

Berry, G., Armitage, P., 1995. Mid- $P$ confidence intervals: a brief review. The Statistician 44, $417-423$. 
Bloesch, J., Jones, T., Reinartz, R., Striebel, B., Holcik, J., Kynard, B., Suciu, R., Williot, P., 2006. Action plan for the conservation of sturgeons (Acipenseridae) in the Danube River Basin. Nat. Environ. 144, 121.

Bolger, D.T., Patten, M.A., Bostock, D.C., 2005. Avian reproductive failure in response to an extreme climatic event. Oecologia 142, 398-406.

Brodie, E.C., Gulland, F.M.D., Greig, D.J., Hunter, M., Jaakola, J., Leger, J.St., Leighfield, T.A., Van Dolah, F.M., 2006. Domoic acid causes reproductive failure in California sea lions (Zalophus californianus). Mar. Mammal Sci. 22(3), 700-707.

Bruch, R.M., Campana, S.E., Davis-Foust, S.L., Hansen, M.J., Janssen, J., 2009. Lake sturgeon age validation using bomb radiocarbon and known-age fish. T. Am. Fish. Soc. 138, 361-372.

Bull, J., Nilsen, E.B., Mysterud, A., Milner-Gulland, E.J., 2009. Survival on the border: a population model to evaluate management options for Norway's wolves Canis lupus. Wildl.

Biol. 15, 412-424.

Calabrese, J.M., Fagan, W.F., 2004. Lost in time, lonely, and single: reproductive asynchrony and the Allee effect. Am. Nat. 164, 25-37.

Donald, P.F., 2007. Adult sex ratios in wild bird populations. Ibis 149, 671-692.

Engelstädter, J., Hurst, G.D.D., 2009. The ecology and evolution of microbes that manipulate host reproduction. Annu. Rev. Ecol. Evol. Syst. 40, 127-149.

Evans, J.P., Keen, E.M., 2013. Regeneration failure in a remnant stand of pignut hickory (Carya glabra) on a protected barrier island in Georgia, USA. Nat. Area. J. 33, 171-176.

Finger, A., Kettle, C.J., Kaiser-Bunbury, C.N., Valentin, T., Doudee, D., Matatiken, D., Ghazoul, J., 2011. Back from the brink: potential for genetic rescue in critically endangered tree. Mol. Ecol. 20(18), 3773-3784. 
Ford, H.A., Walters, J.R., Cooper, C.B., Debus, S.J.S., Doerr, V.A.J., 2009. Extinction debt or habitat change? - Ongoing losses of woodland birds in north-eastern New South Wales, Australia. Biol. Conserv. 142, 3182-3190.

Gessner, J., Freyhof, J., Kottelat, M., 2010. Acipenser nudiventris. The IUCN Red List of Threatened Species. Version 2015.2. <www.iucnredlist.org>. Accessed on 7 January 2016.

Grayson, K.L., Mitchell, N.J., Monks, J.M., Keall, S.N., Wilson, J.N., Nelson, N.J., 2014. Sex ratio bias and extinction risk in an isolated population of tuatara (Sphenodon punctatus). PLoS ONE 9(4), e94214.

Guti, G., 2006. Past and present status of sturgeons in Hungary. Proceedings 36th International Conference of IAD, 143-147. Austrian Committee Danube Research / IAD, Vienna.

Hensel, K., Holčik, J., 1997. Past and current status of sturgeons in the upper and middle Danube River. Environ. Biol. Fish. 48, 185-200.

Holčik, J., (ed) 1989. The freshwater fishes of Europe. AULA Verlag, Wiesbaden, Germany Janssen, J., Jude, D.J., 2001. Recruitment failure of mottled sculpin Cottus bairdi in Calumet Harbor, Southern Lake Michigan, induced by the newly introduced round goby Neogobius melanostomus. J. Great Lakes Res. 27(3), 319-328.

Jarić, I., 2015. Complexity and insidiousness of cryptic function loss mechanisms. Trends Ecol. Evol. 30 (7), 371-372.

Jarić, I., Lenhardt, M., Cvijanović, G., Ebenhard, T., 2009. Acipenser sturio and Acipenser nudiventris in the Danube - extant or extinct? J. Appl. Ichthyol. 25, 137-141.

Jarić, I., Ebenhard, T., Lenhardt, M., 2010. Population Viability Analysis of the Danube sturgeon populations in a VORTEX simulation model. Rev. Fish Biol. Fisher. 20 (2), 219-237.

Kálmán, I., 1961. A 23 és fél kilós tok. Magyar Horgász 15 (7), 1-2. [In Hungarian] 
Kudo, G., Ida, T.Y., 2013. Early onset of spring increases the phenological mismatch between plants and pollinators. Ecology 94(10), 2311-2320.

Loehle, C., Li, B.L., 1996. Habitat destruction and the extinction debt revisited. Ecol. Appl. 63(3), 784-789.

McCarthy, M.A., 1997. The Allee effect, finding mates and theoretical models. Ecol. Model. 103, 99-102.

Peterson, C.H., Fodrie, F.J., Summerson, H.C., Powers, S.P., 2001. Site-specific and densitydependent extinction of prey by schooling rays: generation of a population sink in top-quality habitat for bay scallops. Oecologia 129, 349-356.

Ricciardi, A., Neves, R.J., Rasmussen, J.B., 1998. Impending extinctions of North American freshwater mussels (Unionoida) following the zebra mussel (Dreissena polymorpha) invasion. J. Anim. Ecol. 67, 613-619.

Simonović, P., Budakov, Lj., Nikolić, V., Marić, S., 2005. Recent record of the ship sturgeon Acipenser nudiventris in the middle Danube (Serbia). Biologia 60 (2), 231-233.

Smithers, B.V., Peck, D.R., Krockenberger, A.K., Congdon, B.C., 2003. Elevated sea-surface temperature, reduced provisioning and reproductive failure of wedge-tailed shearwaters (Puffinus pacificus) in the southern Great Barrier Reef, Australia. Mar. Freshw. Res. 54, 973-977. Solow, A.R., 1993. Inferring extinction from sighting data. Ecology 74, 962-964.

Solow, A.R., 2005. Inferring threat from a sighting record. Math. Biosci. 195, 47-55.

Suciu, R., 2009. Specimen of Ship Sturgeon (Acipenser nudiventris) captured alive in the Danube River. World Sturgeon Conservation Society (WSCS). <www.wscs.info $>$. Accessed on 7 January 2016. 
Taylor, B.E., Scott, D.E., Gibbons, J.W., 2006. Catastrophic reproductive failure, terrestrial survival, and persistence of the marbled salamander. Conserv. Biol. 20(3), 792-801.

Vásárhely, I., 1957. Felső-tiszai színtokok - és a Tiszalöki vízilépcsö. [Ship sturgeon catches in the upper Tisza River and the Tiszalok water step] Halászat 4, 105. [In Hungarian]

Warburton, C.L., James, E.A., Fripp, Y.J., Trueman, S.J., Wallace, H.M., 2000. Clonality and sexual reproductive failure in remnant populations of Santalum lanceolatum (Santalaceae). Biol. Conserv. 96, 45-54.

Waters, C.G., Story, R., Costello, M.J., 2013. A methodology for recruiting a giant clam, Tridacna maxima, directly to natural substrata: a first step in reversing functional extinctions? Biol. Conserv. 160, 19-24.

Webb, M.A.H., Williams, J.E., Hildebrand, L.R., 2005. Recovery program review for endangered pallid sturgeon in the Upper Missouri River Basin. Rev. Fish. Sci. 13, 165-176.

Williot, P., Rochard, E., Rouault, T., Kirschbaum, F., 2009. Acipenser sturio recovery research actions in France. In: Carmona, R., et al. (eds.) Biology, Conservation and Sustainable Development of Sturgeons. Springer Science, 247-263.

Xu, S., Ju, J., Zhou, X., Wang, L., Zhou, K., Yang, G., 2012. Considerable MHC diversity suggests that the functional extinction of baiji is not related to population genetic collapse. PLoS ONE 7(1): e30423.

Zhang, H., Wei, Q.W., Du, H., Shen, L., Li, Y.H., Zhao, Y., 2009. Is there evidence that the Chinese paddlefish (Psephurus gladius) still survives in the upper Yangtze River? Concerns inferred from hydroacoustic and capture surveys, 2006-2008. J. Appl. Ichthyol. 25(Suppl. 2), 9599. 
Zhang, H., Wei, Q.W., Du, H., Li, L.X., 2011. Present status and risk for extinction of the Dabry's sturgeon (Acipenser dabryanus) in the Yangtze River watershed: a concern for intensified rehabilitation needs. J. Appl. Ichthyol. 27, 181-185. 
Table 1. Estimated true probability of false rejection of $\mathrm{H}_{0}$ for the test for functional extinction with nominal significance level 0.05 for selected values of beta and sighting frequency; $\mathrm{H}_{0}$ - the species is not functionally extinct at time T; results are based on simulating 2000 samples.

\begin{tabular}{llll}
\hline $\mathrm{N}^{*}$ & $\beta=0.05$ & \multicolumn{2}{c}{$\beta=0.15$} \\
\hline 1 & & 0.031 & 0.051 \\
3 & & 0.021 & 0.048 \\
5 & & 0.036 & 0.048 \\
\hline
\end{tabular}

* Number of sightings in each year with sightings 
Table 2. Estimated power of the test for functional extinction (i.e. probability of true rejection of the $\mathrm{H}_{0}$ ) for different scenarios, applied at the 0.05 significance level; $\mathrm{H}_{0}$ - the species is not functionally extinct at time $\mathrm{T}$; results are based on simulating 1000 samples, with the total duration of 50 years.

Year of functional extinction $\quad \mathrm{N}^{*} \quad \beta=0.05 \quad \beta=0.15$

\begin{tabular}{llll}
\hline 30 & 1 & 0.068 & 0.990 \\
& 3 & 0.719 & 1.000 \\
5 & 0.994 & 1.000 \\
15 & 1 & 0.381 & 0.999 \\
& 3 & 0.971 & 1.000 \\
& 5 & 0.996 & 1.000 \\
\hline
\end{tabular}

${ }^{*}$ Number of sightings in each year with sightings 
Table 3. Sightings of ship sturgeon (Acipenser nudiventris) in the Danube River since 1955, with the estimated birthyears.

\begin{tabular}{cll}
\hline \multicolumn{2}{l}{ Sighting } & \\
\multicolumn{1}{l}{ year } & References & Mean estimated birthyear \\
\hline $1956^{1}$ & Vásárhely, 1957 & 1941 \\
$1957^{1}$ & Vásárhely, 1957 & 1953 \\
$1957^{1}$ & Vásárhely, 1957 & 1949 \\
1957 & Vásárhely, 1957 & 1957 \\
$1961^{1}$ & Kálmán, 1961 & 1944 \\
1975 & Hensel and Holčik, 1997 & 1972 \\
1989 & Hensel and Holčik, 1997 & 1973 \\
1992 & Guti, 2006 & 1982 \\
$1998^{2}$ & Harka pers. comm. & $/$ \\
2003 & Sallai pers. comm. & 1971 \\
2003 & Simonović et al., 2005 & 1974 \\
2005 & Guti, 2006 & 1975 \\
2009 & Suciu, 2009 & 1990 \\
\hline
\end{tabular}

